\title{
Sustainable Nanotechnology and its Relevance to Daily Life
}

Riam Abu-Much

The Academic Arab College of Education, Haifa-Israel

\section{Abstract}

Sustainable nanotechnology is the development of science and technology at the nano-scale, taking into consideration economic, society, and environmental aspects. Nanotechnology is a multidisciplinary field of science that considered as one of the key technologies of the $21^{\text {st }}$ century, which occupies many research centers of great importance, and supports the creation of safe and sustainable advanced materials for the next generation of manufacturing and technology. Different lab activities were carried out for both pre-service and in-service teachers that incorporate nanoscience, sustainability and its relevance to daily life. The activities focused on technological and medical applications of nanostructures aimed to provide high-quality undergraduate research experiences to both attract and retain talented individuals

\section{Formation of Electrical Conductive Films based on Silver Nanoparticles}

Two different colloid solution of silver nanoparticles were prepared, the first one with electrical insulator stabilizer, the second one with electrical conductive polymer.
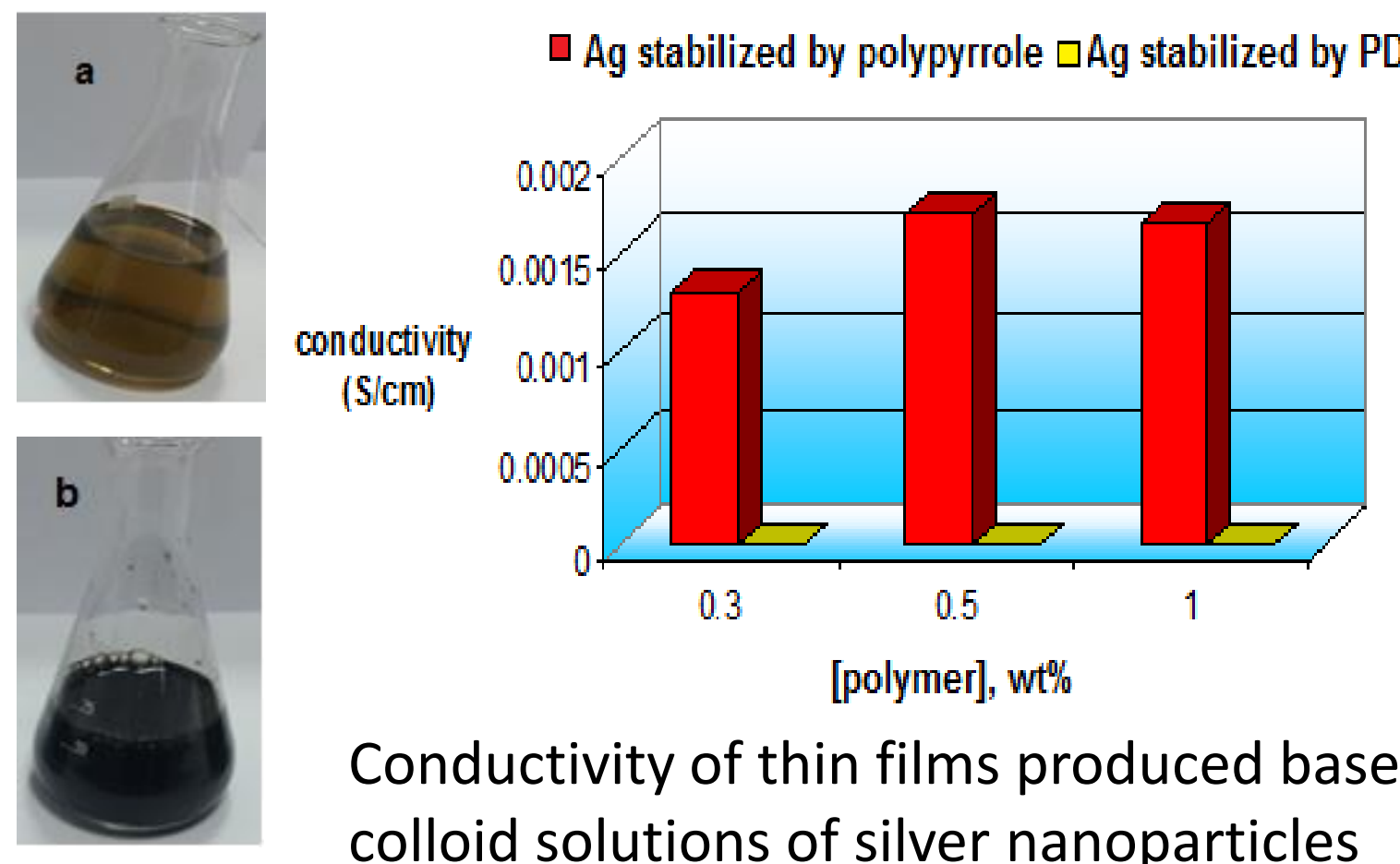

Conductivity of thin films produced based on colloid solutions of silver nanoparticles

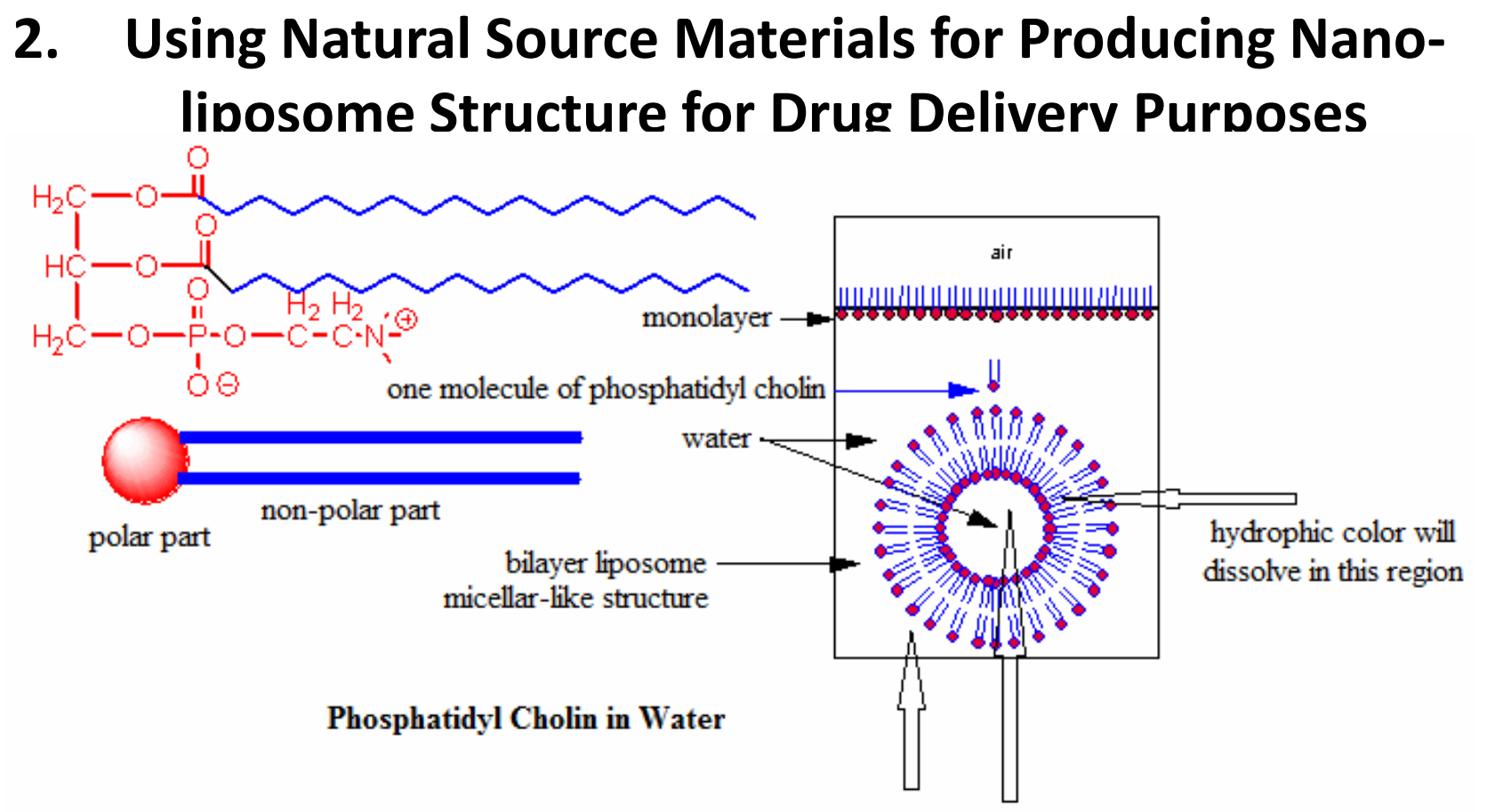

hydrophilic color will dissolve in these regions
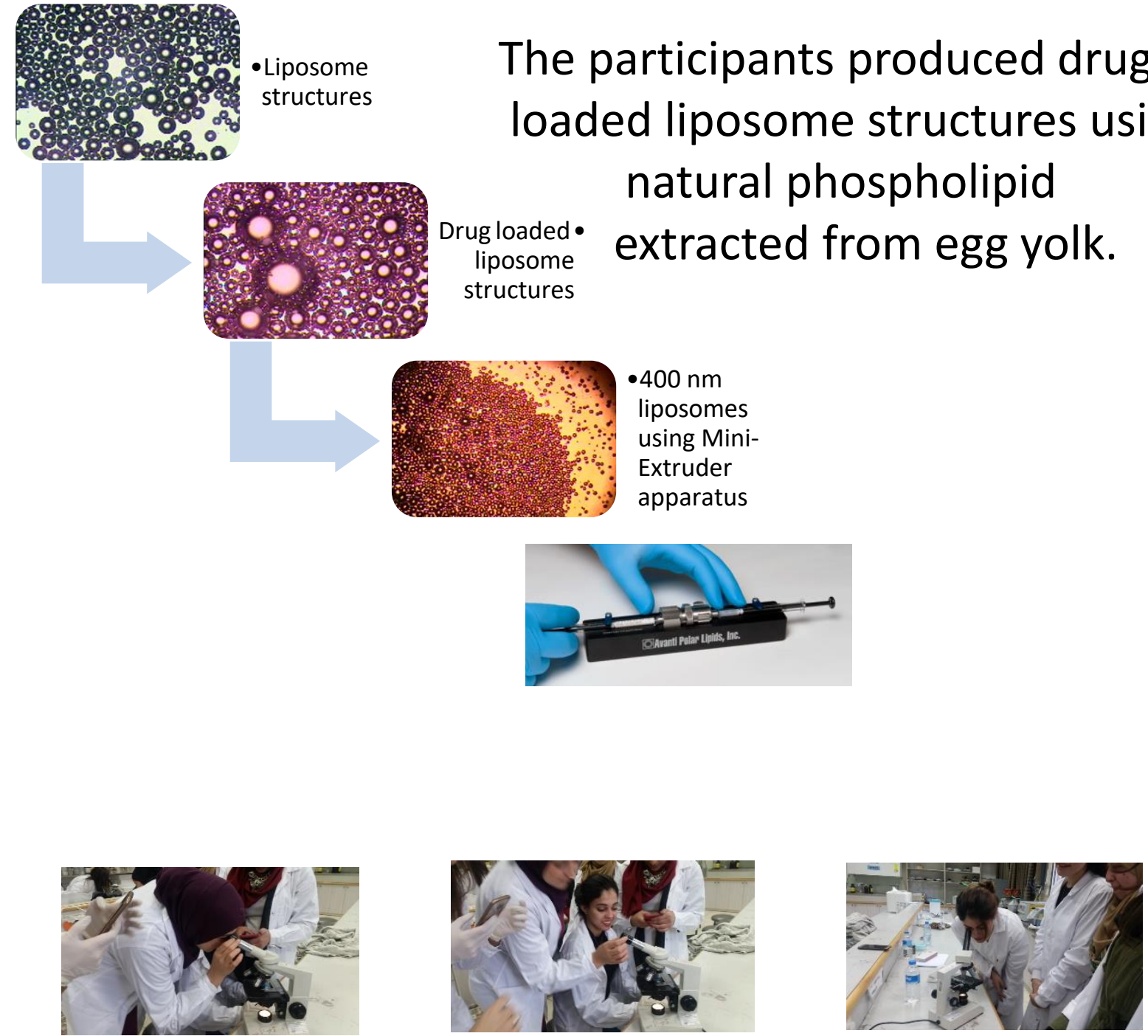

Int. J. Chem. Sci., 2017, 15(4), pp 209-217

J. Chem. Educ., 2013, 90 (9), pp 1207-1211 J. Nano Educ.2016, 22-29 